\title{
Spatio-temporal Characteristics of Disturbance of Land Use Change on Major Ecosystem Function Zones in China
}

\author{
NING Jia ${ }^{1,2}$, LIU Jiyuan ${ }^{1}$, ZHAO Guosong ${ }^{1,2}$ \\ (1. Key Laboratory of Land Surface Pattern and Simulation, Institute of Geographic Sciences and Natural Resources Research, Chinese \\ Academy of Sciences, Beijing 100101, China; 2. University of Chinese Academy of Sciences, Beijing 100049, China)
}

\begin{abstract}
In recent years, because of increasing human activities, ecosystems have been substantially disturbed and their service functions have been greatly compromised. Based on the effect of land use changes on the major ecosystem services, we estimated the ecosystem comprehensive anthropogenic disturbance index (ECADI) and analyzed the spatio-temporal characteristics of changes in the ECADI in China from 1990 to 2010. The average ECADI of the major ecosystem function zones in China in 2010 is approximately 0.382. The ECADI of Northeast China and North China is slightly higher than that of Northwest China and Southwest China. Most zones have slight changes in the ECADI. The average increases of ECADI in the major ecosystem function zones in China from 1990 to 2000 and from 2000 to 2010 are 0.0024 and 0.0002 , respectively. The increase is mainly due to reclamation and urbanization, whereas the decrease is due to the implementation of ecosystem protection policies. During the last 20 years, the ECADI of water resources conservation zones increased first, and then stopped. The ECADI of soil conservation zones increased first, and then declined. The ECADI of sandstorm prevention zones, biodiversity conservation zones and flooding mitigation zones increased continuously. Our results may provide proposals to the government regarding land use planning and ecosystem protection plans in the major ecosystem zones. The major ecosystem function zones in the western part of China have been protected effectively. However, the major ecosystem function zones in the eastern part of China require more protection in the future.
\end{abstract}

Keywords: land use change; major ecosystems services; disturbance; spatiotemporal patterns; China

Citation: Ning Jia, Liu Jiyuan, Zhao Guosong, 2015. Spatio-temporal characteristics of disturbance of land use change on major ecosystem function zones in China. Chinese Geographical Science, 25(5): 523-536. doi: 10.1007/s11769-015-0776-8

\section{Introduction}

The ecosystem is the basic unit of Earth's life support system, and it provides food, timber, fuel, fiber and other products, as well as water purification, soil and water conservation, clean air and other service functions to maintain stability throughout Earth's life support systems. These services are the basic guarantee of human survival and social development (Costanza et al., 1997; Daily, 1997; Ouyang et al., 1999; Millennium Ecosystem Assessment, 2005; Xu et al., 2009; Li et al., 2013). With the better understanding of the importance of ecosystem services gradually deepens, many researchers have investigated the causes, impact factors and management measures of ecosystem services (Battin et al., 2007; Daily and Matson, 2008; Polasky and Segerson, 2009; Gascoigne et al., 2011). Humans take advantage of a variety of services provided by ecosystems, including both natural resources and habitat. At the same time, humans also strongly influence ecosystem services. In addition to some human activities that are conducive to the stability and

Received date: 2015-03-10; accepted date: 2015-05-05

Foundation item: Under the auspices of National Key Basic Research Program of China (No. 2014CB954302), National Science and

Technology Support Plan Project of China (No. 2013BAC03B04)

Corresponding author: LIU Jiyuan. E-mail: liujy@igsnrr.ac.cn

(C) Science Press, Northeast Institute of Geography and Agroecology, CAS and Springer-Verlag Berlin Heidelberg 2015 
improvement of ecosystem services, most activities lead to a series of ecological crises and disasters that threaten human survival and development. Since the industrial revolution, unreasonable activities such as over-cultivating land, overgrazing and deforestation, have appeared as a result of population growth. Moreover, the rapid development of industrialization has greatly changed land use and produced a variety of contaminants. These problems have greatly damaged the abilities of ecosystems to offer various services, including delivering goods (Zhao and Zhang, 2006). The maintenance and continuous enhancement of ecosystem services is a common challenge faced by humans in the new century. The consequences of human activities on ecosystem services have become a prominent issue facing the world and a common concern of human society. The impact of human activities on ecosystem services has therefore received more attention.

Land use changes encompass a wealth of information about human activity. Land use change is the most direct manifestation of the effects of human activities on the natural ecosystem of the Earth's land surface (Mooney et al., 2013). Meanwhile, land use change is also a bond of the interaction between human socio-economic activities and natural ecological processes (Mooney et al., 2013). The process of land use change is closely related to life processes and material cycles on the land surface (Tian et al., 2012). Land use changes affect ecosystem services directly by changing ecosystem types, patterns and ecological processes. Therefore, land use change is an important driving force for changes in ecosystem services (Nelson et al., 2010; Polasky et al., 2011; Wardrop et al., 2011). Because land use change has become the focus of studies on global change, its impacts on ecosystem services have also attracted increasing attention (Folke et al., 2002; Daily et al., 2009; Swetnam et al., 2011). The quantitative assessment of the relationship between changes in ecosystem services and land use changes has become a hot spot of current ecological research (Du et al., 2009; Li et al., 2010).

Disturbance is a widespread natural phenomenon, and plays an important role in the structure, function and dynamics of ecosystem (Hobbs and Huenneke, 1992; Farina, 1998). Disturbance can be divided into natural disturbance and artificial disturbance. Natural disturbance included the fire, the storm, the flood, the volcano eruption and so on. And the artificial disturbance included the deforestation, the farming, the grazing, the fertilization, the dams, the roads, land use change and so on (Chen and Fu, 2000). Early on the 1994, Lee Hannah et al. (1994) has carried out the research about the artificial disturbance on the whole world on a very coarse resolution. The research only divided the whole world into three categories: areas with no disturbance, areas with some disturbance and areas with all disturbances. Since then, there are many researches that are focused on the single disturbance, such as fire (Lv and Tian, 2007; Hu et al., 2013), grazing (Zhou et al., 2012), soil disturbance, nutrient input (Chen et al., 2007) and so on. But those researches are mainly on regional or local scale of the single disturbance. Land use change, which includes the information of other disturbance to some extent, is more complicated than other disturbance. The research before about the disturbance of land use change is mainly about the disturbance of land use change on the biodiversity (Li et al., 2009; Başnou et al., 2013), but rarely on the other ecosystem services. So, it is necessary to estimate the disturbance of land use change on the ecosystems on the whole country scale with a smaller resolution during a long time period.

Nowadays China is assessing ecosystem services nationally at the first time, almost including all the ecosystems on different scales. Meanwhile, a new system of 'ecosystem function conservation areas' in China has been established. The regionalization of ecosystem function conservation areas aimed to focus the conservation and restoration in places with higher major ecosystem services. On the other hand, the regionalization has left the places where high-impact human activities can sustain or enhance for public benefit (Ehrlich et al., 2012). Because of the initiatives, the goals that people harmonize with nature can be reached as well as the goal of alleviating poverty (Li et al., 2011). The regionalization is effectively for integrating conservation and human development. And it is important and beneficial to improve local livelihoods ( $\mathrm{Li}, 2012$ ).

Since the economic reform in 1978, rapid economic development has spurred land use change in China. It has resulted in many ecological problems, such as land degradation and desertification. In recent years, in order to address these serious ecological crises, the government launched a series of ecological restoration pro- 
grams. The implement of those programs have caused significant land use change and a profound impact on the terrestrial ecosystem (Liu et al., 2008). It is particularly important to monitor the effect of land use change on the ecosystem services in recent decades. Based on the effects of human activities on the major ecosystem services, the ecosystem comprehensive anthropogenic disturbance index of 1990, 2000 and 2010 in China is estimated. The study conducted an analysis on the spatiotemporal characteristics of the changes in the ecosystem comprehensive anthropogenic disturbance index (ECADI) caused by land use change on the major ecosystem function zones in China. The aim was to offer proposals to the Chinese government concerning land use planning in the major ecosystem zones.

\section{Materials and Methods}

\subsection{Land use data}

Land use data is obtained from the land use database with a mapping scale of $1: 100000$ developed by the Chinese Academy of Sciences. The primary data source for this land use database was mainly Landsat MSS/ TM/ETM digital images. The database was developed through interactive interpretation in the early 1990s and was updated every five years. So far, land use and land use change data from 1990, 1995, 2000, 2005 and 2010 have been already recorded. The land use data were classified into 25 categories that were subsequently grouped into six classes: cropland, woodland, grassland, water body, built-up land, and unused land. The combined accuracy of the six classes was higher than $90 \%$ (Liu et al., 2010). Land use and land use change for the six classes and their subclasses (such as saline, swamp, and snow) in 1990, 2000 and 2010 were used in this study.

\subsection{Major ecosystem function zones of China}

At present, there are several versions of the major ecosystem function zones of China. In this study, the modified version provided by Ouyang Zhiyun from Research Center for Eco-Environmental Sciences, Chinese Academy of Sciences, is chosen (MEPC and CAS, 2008) (Fig. 1). As delineated by Ministry of Environmental Protection and Chinese Academy of Sciences in 2008, the area of major ecosystem function zones is about $24 \%$ of the whole China's land area and $25 \%$ of its counties. Major ecosystem function zones are designed to secure soils, water resources and biodiversity and to prevent sandstorms and mitigate floods. There are 50 key zones of ecological service functions, which are based on the significance of various ecological function regions for safeguarding the national ecological safety (Table 1). The major ecosystem function zones include 17 water resources conservation zones, 4 soil conservation zones, 7 sandstorm prevention zones, 16 biodiversity conservation zones and 6 flooding mitigation zones (Ouyang et al., 2009; Fu et al., 2013).

\subsection{Ecosystem comprehensive anthropogenic dis- turbance index (ECADI)}

It has been hypothesized that humans have disturbed unused or difficult-to-use ecosystems to a lesser degree, and have played a larger role in the disturbance of cropland and settlement ecosystems (Liu, 1992). Based on the degree of disturbance on different ecosystem types, each ecosystem type was graded and four categories of the disturbance degree index were given (Table 2).

The ecosystem comprehensive anthropogenic disturbance index was calculated as follows:

$$
D=\left(\sum_{i=0}^{3} A_{i} \times P_{i}\right) / 3 / \sum_{i=0}^{3} P_{i}
$$

where $D$ represents the ecosystem comprehensive anthropogenic disturbance index, which ranges from 0 to 1. $A_{i}$ represents the ecosystem disturbance index of the $i$ th ecosystem type; $P_{i}$ represents the percentage of the area of the $i$ th ecosystem type. A higher ECADI indicates greater human disturbance on ecosystems. In other words, a higher ECADI indicates a greater threat to ecosystem services (Zhao et al., 2014).

\section{Results}

\subsection{Spatio-temporal patterns of ECADI in 2010}

The distribution and values of the ECADI for the major ecosystem function zones in 2010 are shown in Fig. 2 and Fig. 3. The mean ECADI of all of the major ecosystem function zones in China was approximately 0.382. In the spatial display, the ECADI of the major ecosystem function zones in Northeast China and North China were slightly higher than the mean, while the ECADI values in Northwest China and Southwest China were much lower than the mean. 


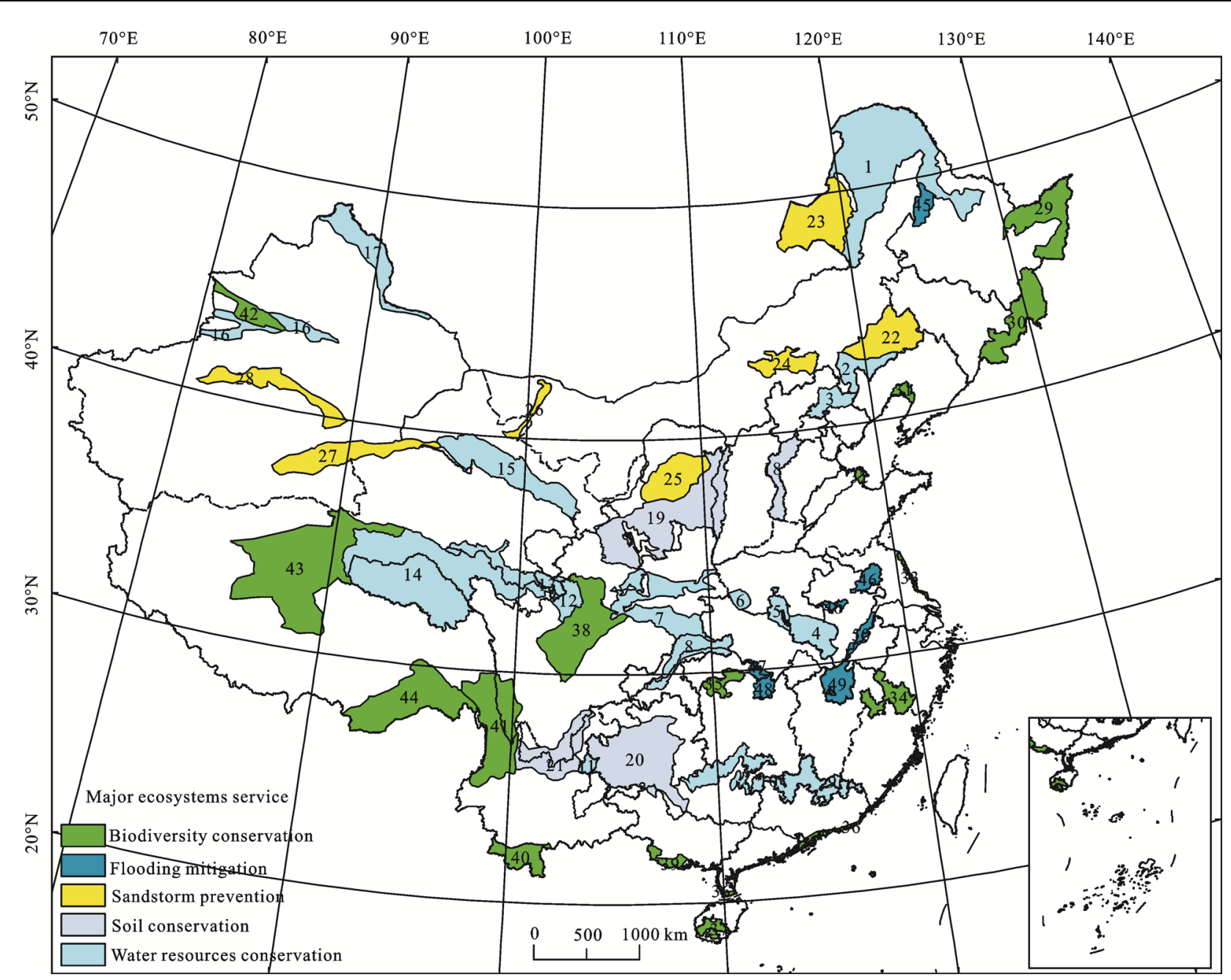

Fig. 1 Map of major ecosystem function zones. The map is provided by Ouyang Zhiyun, Research Center for Eco-Environmental Sciences, Chinese Academy of Sciences. The numbers from 1 to 50 mean the serial numbers of 50 major ecosystem function zones whose names are shown in Table 1

Among the different major ecosystem function zones, the highest mean ECADI, which was approximately 0.556 , was found in the flooding mitigation service zones, while the second highest value of approximately 0.445 was found in the soil conservation service zones. The mean ECADI of the water resources conservation service zones, sandstorm prevention service zones, and biodiversity conservation service zones were similar, with a value of approximately 0.360 . The flooding mitigation service zones are mainly distributed in the middle and lower reaches of the Changiiang (Yangtze) River, which mainly consist of river and lake ecosystems. Owing to the relatively favorable natural conditions in these regions, the economy is relatively developed in these regions. Land use in these regions is high-intensity, and a higher number of lakes and wetlands have been re- claimed. Thus, the disturbance is greater in these than in other zones. The soil conservation service zones are mainly distributed in the Loess Plateau and the Yunnan-Guizhou Plateau. The natural resources are relatively poor in these regions. These regions are over-exploited, owing to the demands of economic and social development. Unreasonable land use and high levels of reclamation, along with transportation, mineral development, urban construction, deforestation, overgrazing and other human activities, create many ecological problems. Surface vegetation degradation, soil erosion and rocky desertification cause serious harm. Therefore, these regions are also with higher disturbance than other zones.

The mean ECADI of all major ecosystem function zones in China in 2010 is also shown in Fig. 3. The high- 
est ECADI, which equals approximately 0.657, appears in Zone 33, which is a biodiversity conservation zone, while the second higher ECADI values are obtained in Zones 46, 47, 31, and 50, which have ECADI values higher than 0.6. These zones are generally in regions with well-developed economies and intensive human activities. Thus, the human disturbance in these regions is high.
The lowest ECADI, which was approximately 0.280 , appears in Zone 12, which is a water resources conservation zone, while the second lowest values are found in Zones 13,26 , and 28. These zones generally have harsh natural conditions. Because of the low population in these regions, the intensity of human activity is mostly low, which causes a low degree of human disturbance.

Table 1 Serial numbers and names of 50 major ecosystem function zones in China

\begin{tabular}{|c|c|c|c|}
\hline Code & Major ecosystem function zone & Code & Major ecosystem function zone \\
\hline 1 & Da Hinggan Mountains Water Resources Conservation Zone & 26 & Heihe River Sandstorm Prevention Zone \\
\hline 2 & Liaohe River Source Water Resources Conservation Zone & 27 & Altun Sandstorm Prevention Zone \\
\hline 3 & Miyun Reservoir Water Resources Conservation Zone & 28 & Tarim River Sandstorm Prevention Zone \\
\hline 4 & Dabie Mountain Water Resources Conservation Zone & 29 & Sanjiang Plain Biodiversity Conservation Zone \\
\hline 5 & $\begin{array}{l}\text { Tongbai Mountain and Huaihe River Source Water Resources } \\
\text { Conservation Zone }\end{array}$ & 30 & Changbai Mountains Biodiversity Conservation Zone \\
\hline 6 & Danjiangkou Reservoir Water Resources Conservation Zone & 31 & Liaohe River Delta Biodiversity Conservation Zone \\
\hline 7 & Qinling-Daba Mountains Water Resources Conservation Zone & 32 & Huanghe River Delta Biodiversity Conservation Zone \\
\hline 8 & Three Gorges Reservoir Water Resources Conservation Zone & 33 & North of Jiangsu Biodiversity Conservation Zone \\
\hline 9 & Dongjiang River Source Water Resources Conservation Zone & 34 & Borderline of Zhejiang-Fujian-Jiangxi Biodiversity Conservation Zone \\
\hline 10 & Nanling Moutains Water Resources Conservation Zone & 35 & Wuling Mountain Biodiversity Conservation Zone \\
\hline 11 & Zhujiang River Source Water Resources Conservation Zone & 36 & Southeast Coastal Mangrove Biodiversity Conservation Zone \\
\hline 12 & Zoigê Water Resources Conservation Zone & 37 & Central South of Hainan Island Biodiversity Conservation Zone \\
\hline 13 & Maqu River Water Resources Conservation Zone & 38 & Minshan-Qionglai Mountains Biodiversity Conservation Zone \\
\hline 14 & Three-River Sources Water Resources Conservation Zone & 39 & Southwest of Guizhou Limestone Biodiversity Conservation Zone \\
\hline 15 & Qilian Mountain Water Resources Conservation Zone & 40 & Xishuangbanna Tropical Rainforest Biodiversity Conservation Zone \\
\hline 16 & Tianshan Mountains Water Resources Conservation Zone & 41 & Three Rivers Parallel Area Biodiversity Conservation Zone \\
\hline 17 & Altay Mountains Water Resources Conservation Zone & 42 & Yili and West of Tianshan Mountains Biodiversity Conservation Zone \\
\hline 18 & Taihang Mountains Soil Conservation Zone & 43 & Beiqiangtang Biodiversity Conservation Zone \\
\hline 19 & Loess Plateau Soil Conservation Zone & 44 & Southwest Tibet Biodiversity Conservation Zone \\
\hline 20 & Karst Soil Conservation Zone & 45 & Songnen Plain Flooding Mitigation Zone \\
\hline 21 & Sichuan-Yunnan Dry-hot Valley Soil Conservation Zone & 46 & Middle and Lower Reaches of Huaihe River Flooding Mitigation Zone \\
\hline 22 & Horqin Sandstorm Prevention Zone & 47 & Jingjiang River Flooding Mitigation Zone \\
\hline 23 & Hulun Buir Grassland Sandstorm Prevention Zone & 48 & Dongting Lake Flooding Mitigation Zone \\
\hline 24 & Yinshan Mountain and Hunshandake Sandstorm Prevention Zone & 49 & Poyang Lake Flooding Mitigation Zone \\
\hline 25 & Mu Us Desert Sandstorm Prevention Zone & 50 & Anhui Wetland along the River Flooding Mitigation Zone \\
\hline
\end{tabular}

Table 2 Classification categories of ecosystem comprehensive anthropogenic disturbance index (ECADI)

\begin{tabular}{cccc}
\hline Disturbance classification index & \multicolumn{2}{l}{ Disturbance level } \\
\cline { 2 - 3 } & 0 & 1 & 2 \\
\hline Ecosystem type & Saline, swamp & Forest, grassland, water (snow and ice excluded) & Farmland \\
\hline
\end{tabular}

Source: Zhao et al., 2014 


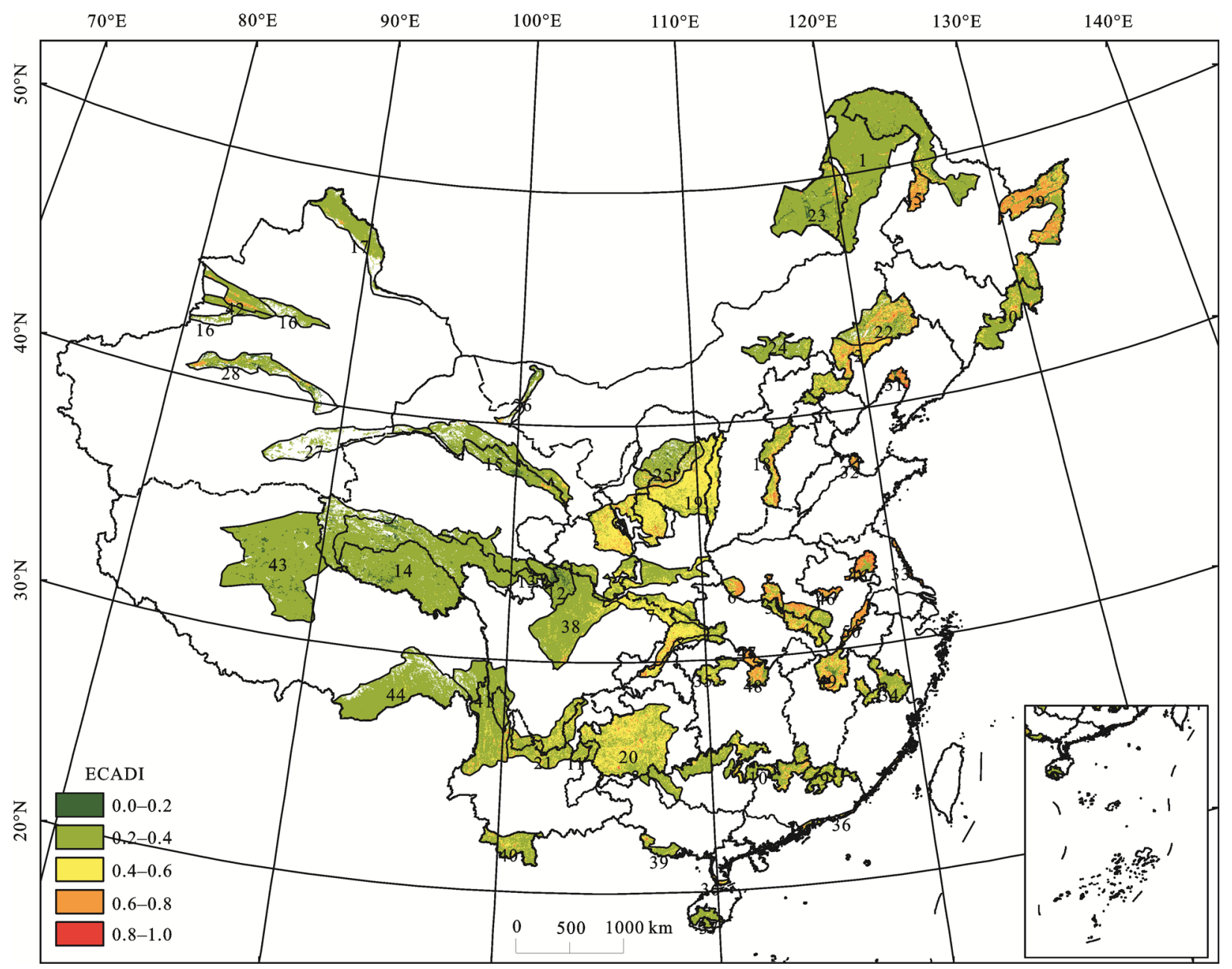

Fig. 2 Distribution of ecosystem comprehensive anthropogenic disturbance index (ECADI) for major ecosystem function zones in 2010. The numbers from 1 to 50 mean the serial numbers of 50 major ecosystem function zones whose names are shown in Table 1

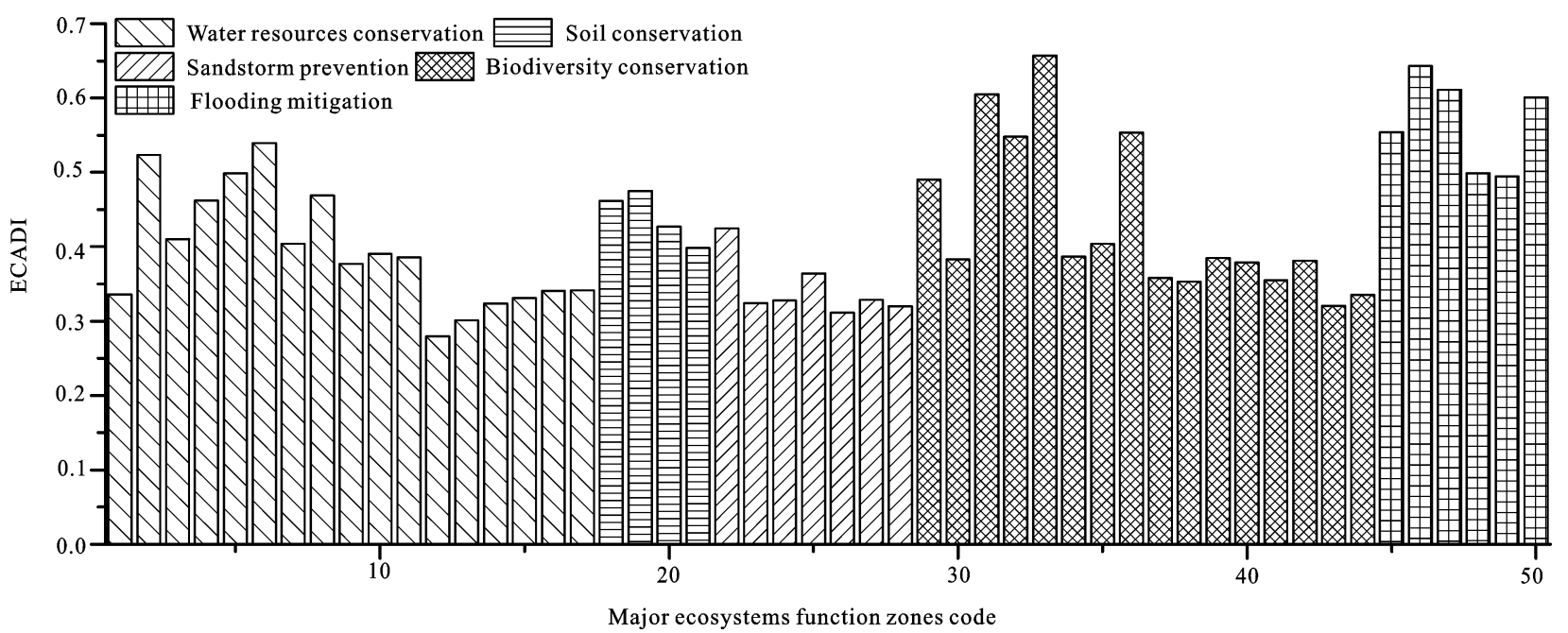

Fig. 3 Mean ecosystem comprehensive anthropogenic disturbance index (ECADI) of all of major ecosystem function zones in 2010. The numbers from 1 to 50 mean the serial numbers of 50 major ecosystem function zones whose names are shown in Table 1 


\subsection{Spatial patterns of changes in ECADI}

The distribution of the changes in the ECADI for the major ecosystem function zones from 1990 to 2000 is shown in Fig. 4 and Fig. 5. The area presenting an increasing ECADI is nearly three-fold higher than the area with decreasing ECADI. The mean increase in the ECADI is 0.0024. The highest significant increase in ECADI, which reached 0.0400, was found in Zone 29. The ECADI in Zone 45 also increased significantly by approximately 0.0275 . The ECADI increases obtained in Zone 2, Zone 22, Zone 31 and Zone 36 are also relatively significant because all are higher than 0.01 . With the exception of Zone 36 in the southeast coastal areas of China, all of the above zones are located in the northeast of China. The increase in the ECADI in these zones is likely the result of the reclamation from woodland and grassland. However, the increase in the ECADI of Zone 36 is because of urbanization. In addition to all of the above zones, which present increases in the ECADI throughout the entire zone, the ECADI also increases in some parts of other zones. For example, the ECADI also increased slightly on the east edge of Zone 23, the eastern part of Zone 1, and the northern part of Zone 30. These zones are located in the northeast of China, and the main reason for the increases is reclamation. In some parts of Zone 46, Zone 4, Zone 5, Zone 6 and Zone 50, which are located in the Changjiang River region, the ECADI also increased significantly. As society develops, which results in urbanization, the amount of built-up land is increasing expanding by occupying other land use types. The ECADI in the western parts of Zone 42 and Zone 19 also increased significantly owing to reclamation. Zone 42 and Zone 28 are located in the northwest of China. Owing to local wet and hot conditions,

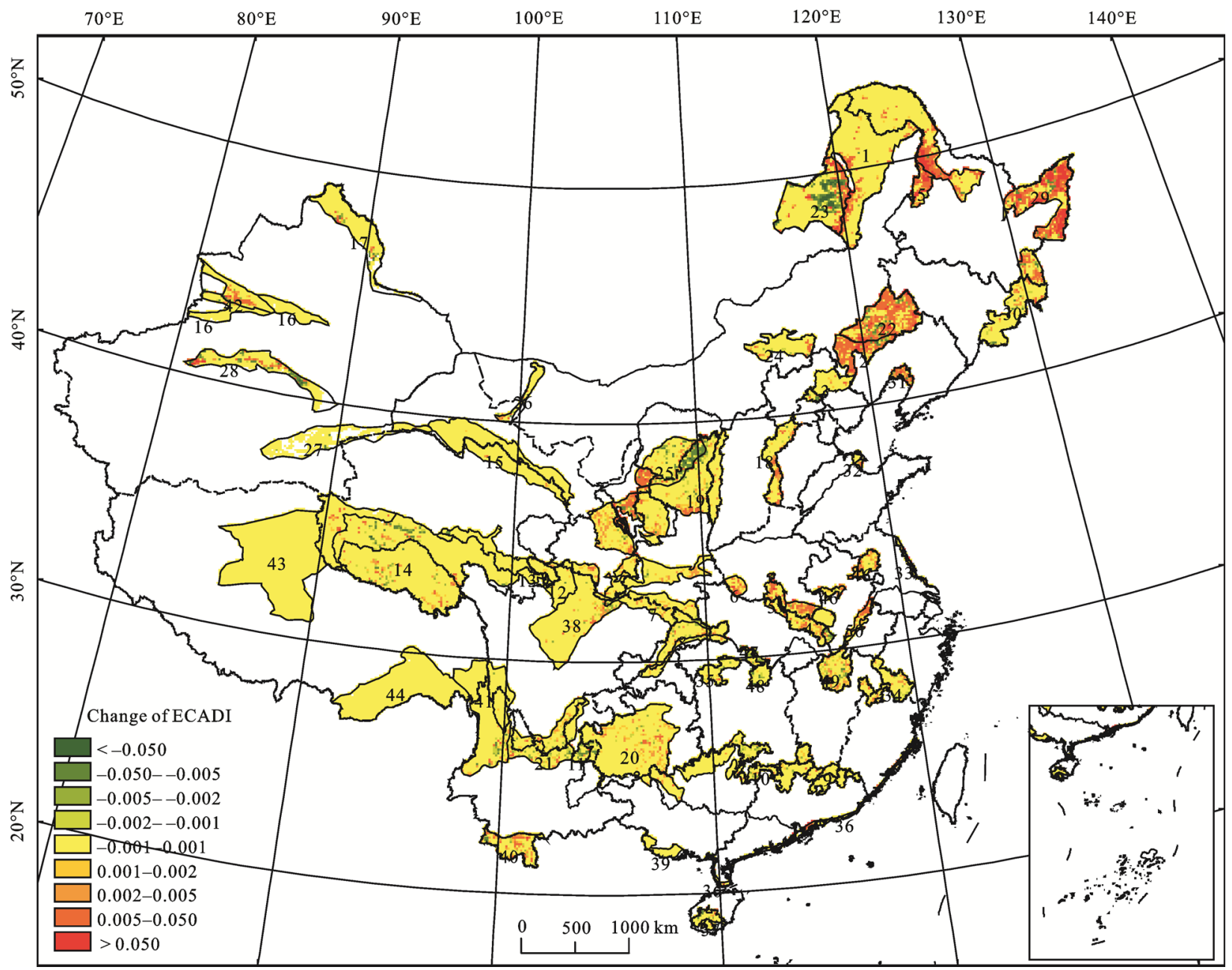

Fig. 4 Distribution of changes in comprehensive anthropogenic disturbance index (ECADI) on major ecosystems service zones from 1990 to 2000 . The numbers from 1 to 50 mean the serial numbers of 50 major ecosystem function zones whose names are shown in Table 1 


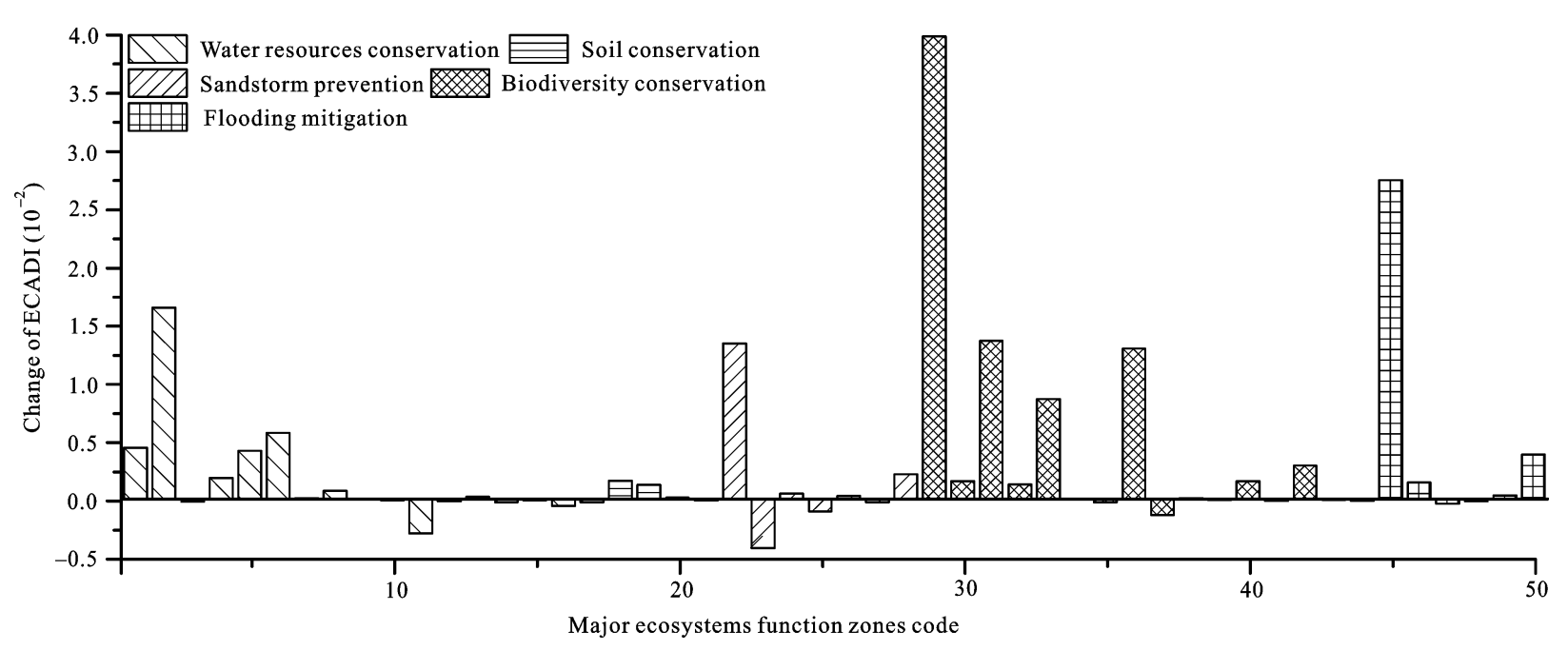

Fig. 5 Changes in comprehensive anthropogenic disturbance index (ECADI) for every major ecosystem service zone from 1990 to 2000. The numbers from 1 to 50 mean the serial numbers of 50 major ecosystem function zones whose names are shown in Table 1

oasis agriculture has developed in these regions. The ECADI of both zones also increased as a result of the reclamation of oasis agriculture. There are also some zones that did not exhibit a great change in the mean ECADI of the entire zone but present small, sporadic areas with increasing ECADI within the zone, e.g., Zone 40, Zone 20, and Zone 14.

There are relatively fewer areas of the major ecosystem function zones with a decreasing ECADI from 1990 to 2000. Among them, the highest and most significant decrease in ECADI was found in Zone 23. The ECADI decreases by up to 0.050 in some parts of Zone 23. Because of the limits of fragile ecological environments, cropland fallowed and changed into woodland and grassland, causing a decrease in the ECADI. Following Zone 23, the ECADI in Zone 11 also decreased significantly. The ECADI in the western part of Zone 25 also decreased significantly by up to 0.050 . The main reason for this is the change from cropland to woodland and grassland. Other zones also have some areas presenting decreases in the ECADI, e.g., Zone 28, Zone 47, Zone 48 , and Zone 14, and this is mainly because of a lower intensity of human activities.

Figures 6 and 7 show the distribution of the changes in the ECADI for the major ecosystem function zones from 2000 to 2010. Contrary to the earlier decade, the area with increasing ECADI is almost four-fifths of the area with decreasing ECADI from 2000 to 2010. The average increase in the ECADI was only 0.0002 , which is approximately one-tenth of that obtained in the previous decade. The areas with increasing ECADI are dis- dispersed, and there are rare cases in which the ECADI increased in the entire region. The analysis of the average ECADI of each zone showed that the average ECADI in Zone 32 increased most significantly by 0.030 . This zone is located in the coastal regions, and the ECADI increased significantly as a result of urbanization. The increase in ECADI in Zone 28 is also obvious, at almost 0.020 . This zone is located in the northwest of China, and the main reason for this increase in the ECADI is the reclamation of oasis agriculture. Because of urbanization, the average ECADI in Zone 36 and Zone 49 increased slightly, by approximately 0.010 . Some zones in the northeastern and central parts of China also present increases in the ECADI, e.g., the central part of Zone 29 and the western parts of Zone 23, Zone 25, Zone 20 and Zone 26. The increased ECADI in these zones is mainly because land use change from woodland and grassland into cropland. The Zone 46, Zone 34, Zone 18 and Zone 36 are located in the western part of China. Owing to the new round of urban expansion, the ECADI in these zones also increased slightly.

The most significant decline in the ECADI was found in Zone 19. The ECADI for the entire zone declined significantly, at an average of approximately 0.010 . The decline was higher than 0.050 in some areas, mainly because the land use changed from cropland into grassland and woodland. The ECADI in some parts of Zone 25, Zone 7, Zone 38, Zone 12, Zone 1 and Zone 20 also declined slightly. The implementation of the Forestry Project, including the Protection of Natural Forests, the Grain for Green Project, 'Three North' and the Changjiang 


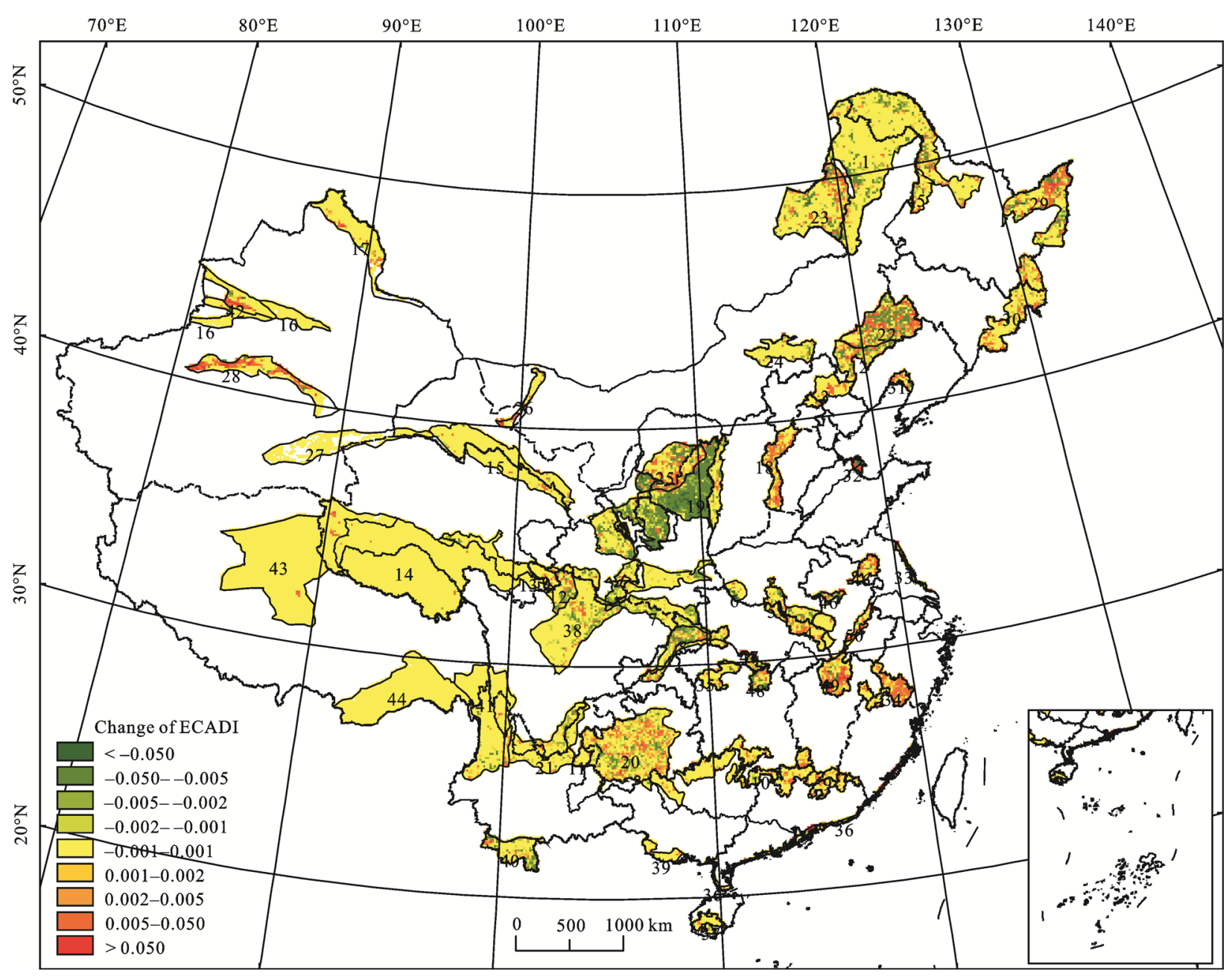

Fig. 6 Distribution of changes in comprehensive anthropogenic disturbance index (ECADI) on major ecosystem function zones from 2000 to 2010. The numbers from 1 to 50 mean the serial numbers of 50 major ecosystem function zones whose names are shown in Table 1

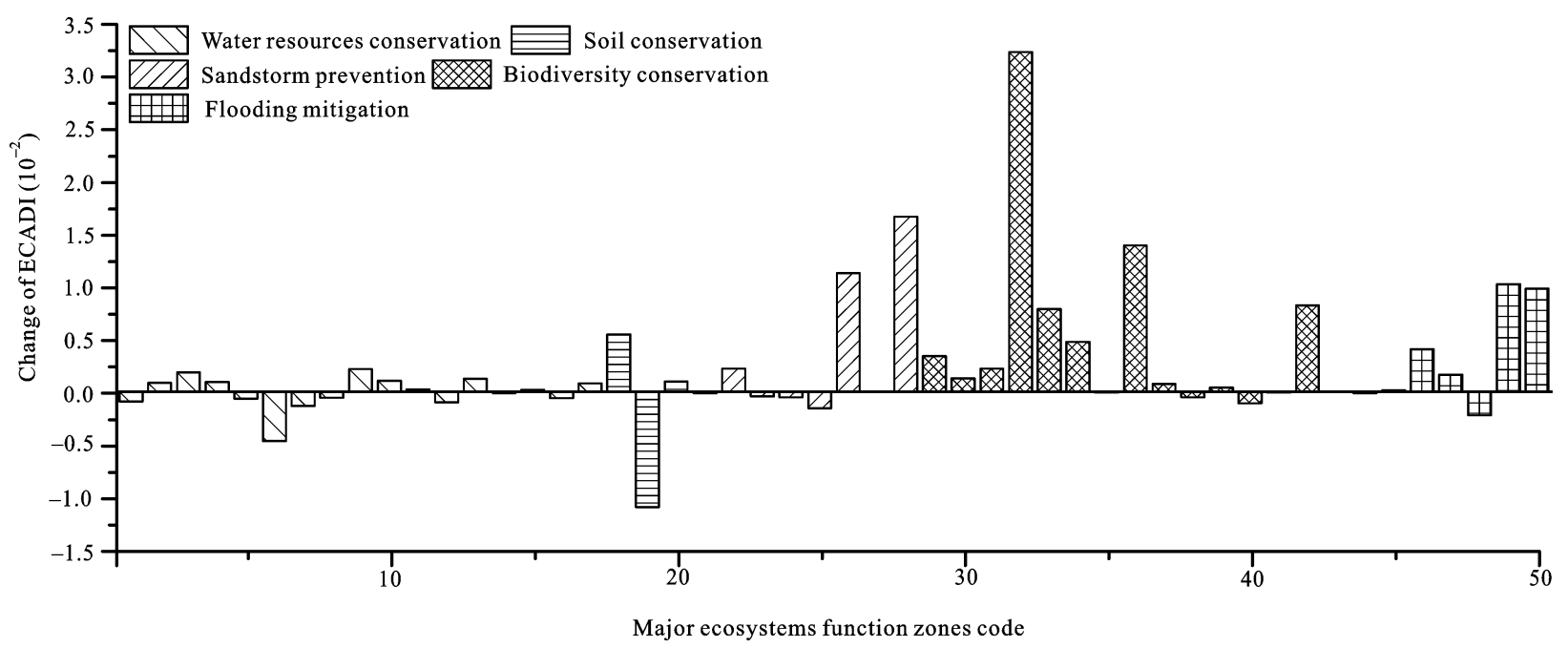

Fig. 7 Changes in comprehensive anthropogenic disturbance index (ECADI) of every major ecosystem service zone from 2000 to 2010. The numbers from 1 to 50 mean the serial numbers of 50 major ecosystem function zones whose names are shown in Table 1 
River Shelterbelt Construction Project is the main reason for these decreases. The most effective project is the Grain for Green Project, which returns cropland to woodland and grassland, leading to a marked decline in the ECADI.

\subsection{Comparison of change in ECADI between two decades}

The overall change in the ECADI for different ecosystem services types from 1990 to 2010 is shown in Fig. 8. From 1990 to 2010, the average ECADI of the major ecosystem function zones in China increased by 0.0026 , showing a gradually increasing trend. The highest increase of approximately 0.0110 was obtained in the flooding mitigation zones, which is the only zone type with a moderately increasing trend. The average ECADI in biodiversity conservation zones, sandstorm prevention zones and water resources conservation zones increased slightly by approximately $0.0052,0.0040$ and 0.0016 , respectively. The ECADI only decreased in soil conservation zones, where it decreased by approximately 0.0027 . In other words, the ECADI in soil conservation zones declined slightly.

From 1990 to 2000, the average ECADI of all ecosystem services types showed an increasing trend. The highest increase of 0.0057 was found in flooding mitigation zones. The flooding mitigation zones are the only zones in which the ECADI increased significantly. The ECADI in the soil conservation zones only increased slightly by 0.0008 , which is the lowest increase obtained in the different zones. The ECADI increases in biodiversity conservation zones, water resources conservation zones and sandstorm prevention zones were 0.0040, 0.0017 and 0.0018 , respectively. Unlike the earlier decade, some zones presented decreasing trends from 2000 to 2010. The highest decrease in the ECADI of approximately 0.0035 was found in the soil conservation zones, which means the ECADI in the soil conservation zones declined significantly. The other decrease in the ECADI was found in the water resources conservation zones. However, this decrease can be neglected because it was only approximately 0.0008 . The highest increase in the ECADI was still observed in the flooding mitigation zones, which presented significant increases of approximately 0.0052 . The ECADI increase in the sandstorm prevention zones which equaled 0.0023 was markedly higher than that obtained in the first decade. However, the increasing trend obtained for the ECADI in the biodiversity conservation zones is slowing because it presented an increase of only 0.0012 .

During the last 20 years, the different major ecosystem service zone types have exhibited various temporal characteristics. The ECADI of water resources conservation zones increased first, and then stopped. The ECADI of soil conservation zones increased first, and then declined. The ECADI of the sandstorm prevention zones, biodiversity conservation zones and flooding mitigation zones increased continuously. However, the ECADI of sandstorm prevention zones increased continuously, weakly at first and then strongly. The ECADI

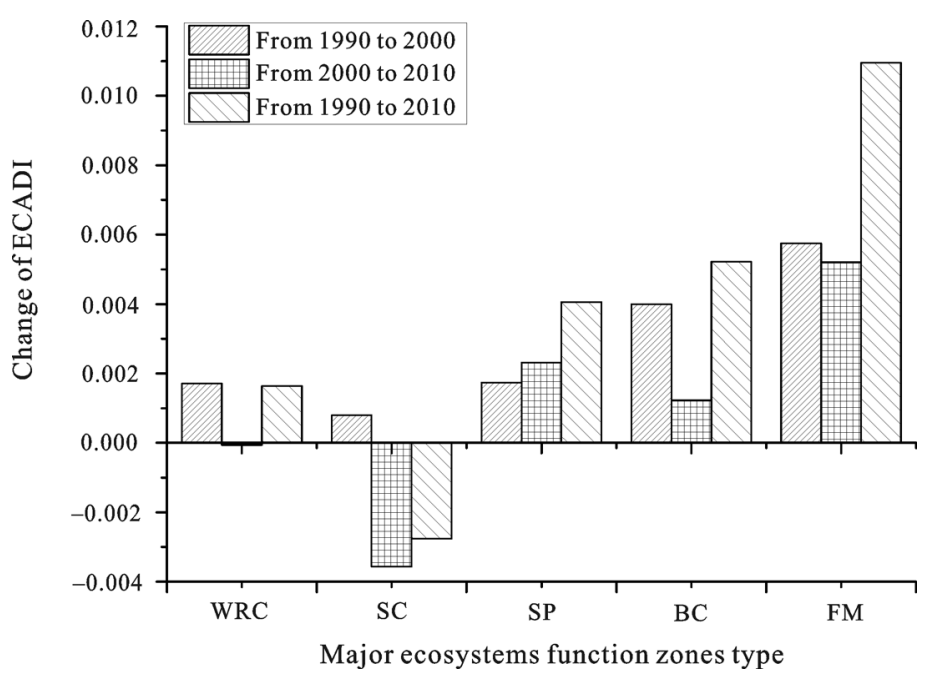

Fig. 8 Comparison of changes in ECADI on major ecosystem function zones between two decades. WRC, SC, SP, BC and FM represent the water resources conservation zones, soil conservation zones, sandstorm prevention zones, biodiversity conservation zones and flooding mitigation zones, respectively 
of biodiversity conservation zones increased continuously, strongly first and then weakly, with a sharply slowing increase. The ECADI of flooding mitigation zones increased continuously, strongly at first and then weakly, and the speed decreased slightly from the first decade to the second decade.

The ECADI of the water resources conservation zones increased slightly from 1990 to 2000, with almost no change from 2000 to 2010 . In the earlier decade, the water resources conservation zones in the northeast of China suffered from massive reclamation; thus, the average ECADI of all water resources conservation zones increased. In the later decade, reclamation in the water resources conservation zones decreased. Some regions implemented projects to protect the ecosystems including the project that turned cropland into woodland and grassland. Thus, the ECADI in the water resources conservation zones has decreased only slightly and can be neglected. The ECADI of the soil conservation zones increased slightly in the first decade, but decreased significantly in the second decade. From 1990 to 2000, the ECADI increased slightly as a result of limited reclamation. However, from 2000 to 2010, owing to the implementation of the Grain for Green Project, most of the land in the soil conservation zones changed from cropland into grassland and woodland. The ecosystem improved and the ECADI decreased significantly. The ECADI of sandstorm prevention zones increased significantly in both decades. In the first decade, reclamation in the sandstorm prevention zones in the northeast of China caused the ECADI to increase significantly. In the second decade, cropland has been returned to grassland and woodland in the sandstorm prevention zones in the northeastern and central regions of China, which caused the ECADI to decrease to some extent. However, severe reclamation is still being undertaken in the sandstorm prevention zones in the northwest of China. Thus, the average ECADI of all sandstorm prevention zones still increased significantly from 2000 to 2010. The ECADI of the biodiversity conservation zones increased continuously, with a significant increasing trend from 1990 to 2000 and a slight increasing trend from 2000 to 2010. In the first decade, owing to reclamation and urbanization, the ECADI increased markedly. In the second decade, owing to the government's emphasis on the conservation of biological diversity, a series of biodiversity protection measures and administrative plans were developed, published and implemented. The reclamation trend in the biodiversity conservation zones in the northeast of China has slowed, but urbanization in the biodiversity conservation zones in the southeast coastal parts of China is still severe, and its range is becoming increasing more expansive. Therefore, the average ECADI of all biodiversity conservation zones increased slightly. In the last 20 years, the ECADI of the flooding mitigation zones continued increasing and the trend decreased. The flooding mitigation zones are mostly located in regions that are more economically developed. In these zones, due to reclamation of the lakes and wetlands and the continued intensification of urban sprawl, built-up land continues to occupy cropland and grassland, and the levels of human disturbance continue to increase.

\section{Discussion}

Some change in the ECADI from 1990 to 2000 and from 2000 to 2010 is very little, even not up to 0.001 . Because of the high accuracy of land use change dataset (Zhang et al., 2012), the errors of the datasets or in the calculation can be neglected. This is mainly because the little percent of area of land use change in the whole area of the major ecosystem function zones. The little amount of the change in the ECADI means that the real land use change is on a little range and extent.

In this study, the same formula was used for estimating the ECADI for different types of ecosystem function zones. However, the same land use change types may have different meanings for the different types of ecosystem services. Therefore, the increase in ECADI may not indicate that the ecosystem services are worsening. For example, in the biodiversity conservation zones, when the land use changes from saline to lake, wetlands or reservoirs, the ECADI increases. Additional reservoirs may destroy the habitats of local animals and plants; in other words, they may have a negative effect on biodiversity conservation services. However, in the flooding mitigation zones, when the same change happens, more lakes, wetlands and reservoirs are better for the ecosystem services. In other words, the increased ECADI has a positive effect on the flooding mitigation services. In future studies, the estimate of ECADI in different ecosystem zones may require slightly different corrections to eliminate deviations. 
Besides, it is better to estimate the ECADI with more details of the ecosystems theoretically. There are great differences in the disturbance on the natural forests and man-made forests, as well as natural water and artificial water. But there have been no such datasets which have the details about the ecosystems on the country scale until now. Because of the limit of the datasets, the estimation of the ECADI with more details on the country scale is not practicable. In future studies, with the development of the datasets, the estimation of ECADI with more details need to be developed.

Human disturbance includes not only land use change but also large-scale construction projects, such as the 'Three Gorges Project', the 'Qinghai-Tibet Railway', and the 'South-to-North Water Diversion Project'. The implementation of such projects can greatly disturb the ecosystems. In future studies, the buffer along these projects can be created to quantify the disturbance caused by the projects. Finally, the disturbance from land use change and other human activities is combined into the ecosystem comprehensive anthropogenic disturbance index.

The spatio-temporal characteristics of the changes in the ECADI on the major ecosystem function zones can provide some knowledge regarding how to protect the ecosystems and ecosystem services. This information can also offer proposals to the government regarding land use planning in the major ecosystem zones. In water resources conservation zones, protecting and restoring the natural vegetation is a practical and effective way to improve the water resources conservation services. In soil conservation zones, returning cropland to forests and returning grazing land to pasture can improve the soil conservation services. In sandstorm prevention zones, returning the cropland to grassland is an effective method for preventing soil loss. In biodiversity conservation zones, it is necessary to decrease the human disturbance as much as possible and maintain the integrity of ecosystems to conserve biological biodiversity. In flooding mitigation zones, returning cropland to lakes is useful for improving the flooding mitigation services.

\section{Conclusions}

In this study, based on the effect of human activities on the major ecosystem services, we estimated the ECADI in China in 1990, 2000 and 2010. Then we analyzed the spatio-temporal characteristics of the changes in the ECADI caused by land use change on the major ecosystem function zones on both the national and regional scales. The main conclusions are as follows:

The average ECADI of the major ecosystem function zones in China in 2010 was approximately 0.382 . The ECADI in Northeast China and North China is slightly higher than the mean, while the ECADI in Northwest China and Southwest China is markedly lower than the mean. Among the different major ecosystem function zones, the highest mean ECADI of approximately 0.556 was observed in the flooding mitigation service zones. The soil conservation service zones presented the second highest mean ECADI of approximately 0.445.

The mean increase in ECADI from 1990 to 2000 and from 2000 to 2010 in China is 0.0024 and 0.0002 , respectively. In the earlier decade, the area with increasing ECADI was nearly three-fold higher than the area with decreasing ECADI. The increasing ECADI was mainly found in the northeast of China due to the reclamation of woodland and grassland. Only a few zones were found to exhibit a declining ECADI, and these are scattered in the northeast and central regions of China. This is mainly due to fallow cropland and cropland changing into grassland and woodland. In the later decade, the area with increasing ECADI was almost a quarter of the area with decreasing ECADI. The increasing ECADI was mainly observed in the southeast coastal regions. The built-up areas expanded, occupying cropland, grassland and woodland and causing the ECADI to increase. The areas with decreasing ECADI are located in the central regions of China. The decreases are mainly due to the implementation of forestry projects, such as returning cropland to woodland and grassland.

There are great variations in temporal characteristics among the different major ecosystem service zone types in China. The ECADI of water resources conservation zones increased first, and then stop. The ECADI of soil conservation zones increased first, and then declined. The ECADI of sandstorm prevention zones increased continuously, weakly at first and then strongly. The ECADI of biodiversity conservation zones increased continuously, strongly at first and then weakly, with a sharply slowing increase. The ECADI of flooding mitigation zones increased continuously, strongly at first and then weakly, and the speed decreased slightly from the 
first decade to the second decade.

The change in the ECADI for the major ecosystem function zones can reflect the protection status of the ecosystem zones. Some major ecosystem function zones have been effectively protected, with human disturbance generally declining, as reflected by a decrease in the ECADI, which is in favor of the maintenance and growth of ecosystem services. However, there remain many major ecosystem function zones with poor protection because human disturbances continued increasing, as reflected by a higher ECADI. The maintenance of the ecosystem services in those zones faces great challenges. Therefore, it can be concluded that the biodiversity conservation zones have been protected to some extent because the increasing disturbance trend has been reversed. However, the sandstorm prevention zones and the flooding mitigation zones have not received adequate and effective protection, and the human disturbance increased continuously in these zones. By examining the spatial characteristics of the entire country, it is concluded that the major ecosystem function zones in the western part of China have been protected effectively. Their disturbance has generally declined. On the contrary, the disturbance to major ecosystem function zones in the eastern part of China increased markedly, and these regions require more protection in the future.

\section{References}

Başnou C, Alvarez E, Bagaria G et al., 2013. Spatial patterns of land use changes across a Mediterranean metropolitan landscape: implications for biodiversity management. Environmental Management, 52(4): 971-980. doi: 10.1007/s00267013-0150-5

Battin J, Wiley M W, Ruckelshaus M H et al., 2007. Projected impacts of climate change on salmon habitat restoration. Proceedings of the National Academy of Sciences of the United States of America (PNAS), 104(16): 6720-6725. doi: 10. 1073/pnas.0701685104

Chen Liding, Fu Bojie, 2000. Ecological signif icance, characteristics and types of disturbance. Acta Ecologica Sinica, 20(4): 581-586. (in Chinese)

Chen Xiaoyan, Liang Zongsuo, Du Feng et al., 2007. The effect of disturbance on the structure and form of three typical communities in Loess hilly region of the northern of Shanxi Province. Acta Ecologica Sinica, 27(7): 3061-3071. (in Chinese)

Costanza R, dArge R, deGroot R et al., 1997. The value of the world's ecosystem services and natural capital. Nature, 387(6630): 253-260. doi: 10.1038/387253a0

Daily G C, 1997. Nature's Services: Societal Dependence on
Natural Ecosystems. Washington D. C.: Island Press.

Daily G C, Matson P A, 2008. Ecosystem services: from theory to implementation. PNAS, 105(28): 9455-9456. doi: 10.1073/ pnas.0804960105

Daily G C, Polasky S, Goldstein J et al., 2009. Ecosystem services in decision making: time to deliver. Frontiers in Ecology and the Environment, 7(1): 21-28. doi: 10.1890/080025

Du Z, Shen Y, Wang J et al., 2009. Land-use change and its ecological responses: a pilot study of typical agro-pastoral region in the Heihe River, Northwest China. Environmental Geology, 58(7): 1549-1556. doi: 10.1007/s00254-008-1656-7

Ehrlich P R, Kareiva P M, Daily G C, 2012. Securing natural capital and expanding equity to rescale civilization. Nature, 486: 68-73. doi: 10.1038/nature11157

Farina A, 1998. Principles and Method in Landscape Ecology. London: Chapman and Hall.

Folke C, Carpenter S, Elmqvist T et al., 2002. Resilience and sustainable development: building adaptive capacity in a world of transformations. Ambio, 31(5): 437-440. doi: 10.1579/00447447-31.5.437

Fu Bojie, Liu Guohua, Ouyang Zhiyun, 2013. Ecological Regionalization in China. Beijing: Science Press. (in Chinese)

Gascoigne W R, Hoag D, Koontz L et al., 2011. Valuing ecosystem and economic services across land-use scenarios in the Prairie Pothole Region of the Dakotas, USA. Ecological Economics, 70(10): 1715-1725. doi: 10.1016/j.ecolecon.2011.04. 010

Hobbs R J, Huenneke L F, 1992. Disturbance, diversity, and invasion: implications for conservation. Conservation Biology, 6(3): 324-337. doi: 10.1046/j.1523-1739.1992.06030324.x

$\mathrm{Hu}$ Haiqing, Wei Shujing, Sun Long et al., 2013. Interaction among climate change, fire disturbance and ecosystem carbon cycle. Arid Land Geography, 36(1): 57-75. (in Chinese)

Lee Hannah, David Lohse, Charles Hutchinson et al., 1994. A Preliminary Inventory of Human Disturbance of World Ecosystems. Ambio, 23(4-5): 246-250.

Li J, 2012. Rural Household Livelihoods and Environmental Sustainability in the West of China. Beijing: Social Sciences Academic Press. (in Chinese)

Li J, Feldman M, Li S et al., 2011. Rural household income and inequality under the Sloping Land Conversion Program in western China. PNAS, 108(19): 7721-7726. doi: 10.1073/pnas. 1101018108

Li T, Li W, Qian Z, 2010. Variations in ecosystem service value in response to land use changes in Shenzhen. Ecological Economics, 69(7): 1427-1435. doi: 10.1016/j.ecolecon.2008.05. 018

Li Yanmei, Niu Dong, Zhang Zhiqiang et al., 2009. Review of international scientific programmes and frontiers of biodiversity research. Acta Ecologica Sinica, 29(4): 2115-2123. (in Chinese)

Li Yifeng, Luo Yuechu, Liu Gang et al., 2013. Effects of land use change on ecosystem services, a case study in Miyun reservoir watershed. Acta Ecologica Sinica, 33(3): 726-736. (in Chinese)

Liu J, Li S, Ouyang Z Y et al., 2008. Ecological and socioeco- 
nomic effects of China's policies for ecosystem services. PNAS, 105(28): 9477-9482. doi: 10.1073/pnas.0706436105

Liu Jiyuan, 1992. Land Use in the Tibet Autonomous Region. Beijing: Science Press. (in Chinese)

Liu Jiyuan, Zhang Zengxiang, Xu Xinliang et al., 2010. Spatial patterns and driving forces of land use change in China during the early 21st century. Journal of Geographical Sciences, 20(4): 483-494. doi: 10.1007/s11442-010-0483-4

Lv Aifeng, Tian Hanqin, 2007. Interaction among climatic change, fire disturbance and ecosystem productivity. Journal of Plant Ecology, 31(2): 242-251. (in Chinese)

Millennium Ecosystem Assessment, 2005. Ecosystems and Human Well-being. Washington D. C.: Island Press.

Ministry of Environmental Protection of the People's Republic of China (MEPC), Chinese Academy of Sciences (CAS), 2008. National Ecosystem Function Regionalization. (in Chinese)

Mooney H A, Duraiappah A, Larigauderie A, 2013. Evolution of natural and social science interactions in global change research programs. PNAS, 110(supp. 1): 3665-3672. doi: 10. 1073/pnas. 1107484110

Nelson E, Sander H, Hawthorne P et al., 2010. Projecting global land-use change and its effect on ecosystem service provision and biodiversity with simple models. PLOS ONE, 5(12): e14327. doi: 10.1371/journal.pone.0014327

Ouyang Zhiyun, Wang Rusong, Zhao Jingzhu, 1999. Ecosystem services and their economic valuation. Chinese Journal of Applied Ecology, 10(5): 635-640. (in Chinese)

Ouyang Zhiyun, Zheng Hua, Huang Baorong et al., 2009. Regional Ecological Assessment and Ecosystem Service Zoning. Beijing: China Environmental Science Press. (in Chinese)

Polasky S, Nelson E, Pennington D et al., 2011. The Impact of land-use change on ecosystem services, biodiversity and returns to landowners: a case study in the State of Minnesota. Environmental \& Resource Economics, 48(2): 219-242. doi: 10.1007/s10640-010-9407-0
Polasky S, Segerson K, 2009. Integrating ecology and economics in the study of ecosystem services: some lessons learned. Annual Review of Resource Economics, 1: 409-434. doi: 10.1146/annurev.resource.050708.144110

Swetnam R D, Fisher B, Mbilinyi B P et al., 2011. Mapping socio-economic scenarios of land cover change: a GIS method to enable ecosystem service modelling. Journal of Environmental Management, 92(3): 563-574. doi: 10.1016/j.jenvman. 2010.09.007

Tian H Q, Chen G, Zhang C et al., 2012. Century-scale response of ecosystem carbon storage to multifactorial global change in the southern United States. Ecosystems, 15: 674-694.

Wardrop D H, Glasmeier A K, Peterson-Smith J et al., 2011. Wetland ecosystem services and coupled socioeconomic benefits through conservation practices in the Appalachian Region. Ecological Applications, 21(3): S93-S115.

Xu H G, Tang X P, Liu J Y et al., 2009. China's progress toward the significant reduction of the rate of biodiversity loss. BioScience, 59(10): 843-852. doi: 10.1525/bio.2009. 59.10.6

Zhang Zengxiang, Zhao Xiaoli, Wang Xiao, 2012. Land Use Remote Sensing Monitoring in China. Beijing: Star Map Press. (in Chinese)

Zhao Guosong, Liu Jiyuan, Kuang Wenhui et al., 2014. Disturbance impacts of land use change on biodiversity conservation priority areas across China during 1990-2010. Acta Geographica Sinica, 69(11): 1640-1650. (in Chinese)

Zhao Shidong, Zhang Yongmin, 2006. Ecosystems and human well-being: the achievements, contributions and prospects of the Millennium Ecosystem Assessment. Advances in Earth Science, 21(9): 865-872. (in Chinese)

Zhou Ling, Shangguan Tieliang, Guo Donggang et al., 2012. Response of species diversity in Caragana Korshinskii communities to climate factors and grazing disturbance in Shanxi, Shaanxi, Ningxia and Inner Mongolia. Acta Ecologica Sinica, 32(1): 111-122. (in Chinese) 